\title{
Shock, Therapy, and Postcommunist Transitions
}

\author{
Anca Pusca*
}

This article explores how the concept of shock has been used in connection to processes of social change and transition, and argues that a wider exploration of the concept in fields other than political science and international relations can provide us with important insights into the individual and collective impacts of transitions. Although criticizing the idea of shock as therapy, the article presents a number of alternative uses of shock that can be particularly insightful for understanding often contradictory behaviors that characterize periods of transition, as well as a series of dangerous consequences of attempts to deal with shock through various techniques of distancing, distraction, and normalization. KeYwORDs: shock therapy, social change, postcommunism, normalization

In Saint Petersburg, Yevgenia Popova is reviving the old medical practice of shock therapy, with notable success. The process is aimed at treating people suffering from stress and various phobias, and involves the administration of a series of electric shocks that force the person to increase their ability to lower the physical effects of the shock through their own power of concentration. The effects of the electric shock are represented on a screen by a series of oscillating lines that, as Popova explains, "a person can consciously calm or straighten." She argues that "once this has been achieved, the individual's chances of accomplishing any given task in everyday life or at work increase significantly." 1

In economics, a different form of "shock therapy" was used to treat the emerging postcommunist societies. The term was used to describe a series of painful economic reform processes that involved

*Marie Curie Research Fellow, University of Birmingham, UK. E-mail: ancapusca@ gmail.com 
"immediate price liberalization, immediate privatization, immediate establishment of an independent central bank, immediate achievement of a balanced budget, immediate introduction of free trade and immediate establishment of a fully convertible flexible currency." ${ }^{2}$ The shock came both from the intended as well as unintended effects of these reforms, particularly the rising inflation, unemployment, and instances of corruption throughout public institutions, the most painful of which were probably felt in the medical, educational, and local government contexts. The patients were in this case entire societies, seeking, and often failing, to control increasing doses of shock over which they had little or no control. The illness that the shock was trying to cure in this case was the chronic economic malaise that communism had forced on these societies. Therapy was intended to produce not only a more prosperous economy, but also a whole new political and economic management structure that would lead these societies toward "democracy."

Subsequent debates about shock therapy focused on questions surrounding the speed of implementation, especially whether gradualism would have been better, ${ }^{3}$ or on analyses exploring the human, economic, or political cost of the therapy. ${ }^{4}$ Given that even the main proponents of the therapy, such as Jeffrey Sachs, an advisor to the governments of a number of transitioning governments, from Bolivia, to Poland, to Russia, ${ }^{5}$ hesitated between supporting the practice and arguing against its improper implementation, particularly because financial assistance "was very small and financial aid totally inflexible." 6 It is no surprise that the "patients" (mainly postcommunist societies) were equally confused in their acceptance and reaction to the therapy. While initially supportive, the governments that helped implement economic shock therapy throughout Central and Eastern Europe were voted out one after the other in order to make room for social democratic and neocommunist parties that promised a slower pace of reform and a greater focus on economic relief. From Poland to the Czech Republic, Bulgaria, Russia, Albania, and Estonia, people rebelled against shock therapy, using their electoral vote to clearly state that they could no longer manage the upheaval. ${ }^{7}$

Faced with this backlash, the economists who proposed the therapy turned to various metaphorical devices in their defense. They argued that "you can't make an omelet without breaking a few eggs," "you don't cross a chasm in two jumps," "they need[ed] a strong dose of medicine quickly," "if a house is on fire, you don't tell the fire brigade to pour water slowly," and "bitter medicine is easier to take in one dose than in a prolonged series of doses." 9 In the meantime, postcommunist societies were left to endure the consequences and slowly pick themselves up. However, the therapy may have left deeper 
scars than are visible today. The relative success of much of Central and Eastern Europe hides many stories of difficult compromises and the development of coping mechanisms that might not be altogether advisable or healthy.

The choice of the word therapy to describe the painful and challenging process of economic reform seems somewhat misplaced, particularly in the context of a complete collapse of one's social security network, destruction of all that appeared normal and familiar, and a drastic drop in overall living standards. If, as in Popova's biological treatment, this economic shock therapy was implemented in order to test and improve the levels of endurance in these populations, it certainly managed to do so, although it is unclear for whose benefit. Endurance and adjustment to shock may have come at a higher cost than initially envisioned. Faced with inflation levels that within less than three years turned the amount of money that could buy a new car into the price of a kilo of tomatoes, and with overall loss of job security that forced brain surgeons and rocket scientists to become cab drivers, people endured the therapy rather stoically. ${ }^{10}$ They relied mainly on an increasingly "thicker skin" that allowed for a certain level of indifference or apathy toward change, as well as on an increasing distrust of public institutions that no longer appeared to protect their interests. Instead of relying on each other, as many had done during communism, they adopted more pragmatic, individual approaches that led many to yearn nostalgically for the past. ${ }^{11}$

One of the main consequences of shock therapy was to disrupt the newly developed sense of solidarity and enthusiasm that immediately followed the Central and East European revolutions, and to turn the fight for liberty and democracy into a fight for survival. The degree of disappointment that followed was as high as that of the initial enthusiasm that surrounded the fall of the iron curtain. While people learned to adjust and control the increasing fluctuations of shock, they did so at a high cost: loss of confidence in the democratic reform process and increasing reliance on nondemocratic means to achieve the economic security they desired. The effects of shock, however, seem to go far beyond this, and a better understanding of these effects requires a more sustained exploration of the processes producing the shock. Specifically, in this article I focus on a series of different interpretations of shock-as a form of distancing, distracting, and normalizating - each of which approaches the experience of transition as an individual and collective struggle to deal with change. By engaging with some of the creative ways in which people have learned to cope with change, I hope to provide not only a critique of how shock came to be understood as "therapeutic"-a term that clearly serves to downplay the pain and struggle that those subjected 
to the shock of transitions have had to endure-but also to offer a different view of how resistance to shock has created a new type of individual as well as new collectivities.

\section{Interpretations of Shock in Social Transitions}

The concept of shock has a rich history that follows a number of different trajectories: from negative to positive, and from individual to collective. What these different engagements with the concept of shock have in common is an acceptance of its basic meaning as an increase in a number of different stimuli that affect the way in which an individual or a collective perceive and react to the surrounding reality. Shock is thus something that is for the most part inflicted from the outside, an intruding element to which the senses respond in a number of ways. Almost by definition, something is shocking to the extent that it extends beyond the realm of "normality" or what is to be expected. Shocking experiences thus mark a departure from everyday life, forcing an individual or a collective to come up with new responses and coping mechanisms to the intruding elements. These different responses have provided fertile ground for analysis for both psychologists and for scholars of modernity. Their interpretations of the phenomena of shock may serve to expand the otherwise narrow analyses of shock therapy deployed in the context of social transitions. Understanding the role of shock in times of transition or rapid social change may provide useful insights for the explanation of a series of contradictory behaviors that characterize these periods (such as overwhelming support for change followed by a swift nostalgia for the past) as well as a series of pathological tendencies among individuals and collectives in transition societies (from an increase in suicides, crime, and corruption, to depression or obsessive behavior), especially in view of the negative effects that have long been noted by analysts of "democratic transitions." 12

While shock treatments have a long history, I am concerned here with those that are directly connected to processes of modernity and social changes dating roughly from the nineteenth century. Within this period, shock mainly has been associated with the rise of modern technologies, particularly technologies of war, and with the development of modern cities. Shock was once closely associated with the notion of trauma: with physical trauma as a result of war, and, later, psychological trauma as a result of a series of different modern technologies and transformations that significantly changed the structure of society and the individual experience within this structure. 
In his renowned essay on the storyteller, Walter Benjamin gives an excellent example of the extent to which the shocking experience of war can challenge traditions that are thousands of years old, such as storytelling. Traumatized soldiers returning from the front, as well as traumatized families dealing with the death of loved ones and shortages of basic necessities, find themselves in a silenced state, whereby communication is implicit in nonverbal acts of suffering as opposed to verbal expressions of pain. Benjamin argues that it is precisely this silence that created an incentive for an increase in non-oral communication, especially through printed text, rather than the traditional act of storytelling. The rise of the novel, the newspaper, and other forms of printed text is attributed to their ability to allow the individual to communicate in a nonpersonal manner, whereby tears, pain, and disturbances could be artfully hidden and to a certain extent avoided. The decline of the storytelling tradition also marks the end of a particular form of solidarity not only within the family but also within larger social groups. Shock was thus perceived to have a significant influence on the way in which people relate to each other. ${ }^{13}$

This serves as an excellent example for understanding how shock can challenge particular traditions and lead to unexpected changes in the way in which social solidarities are built or broken. As almost intrinsic to change, shock involves different kinds of trauma, but not all traumas need to be experienced negatively. In fact, as Yevgenia Popova suggested, shock can be managed and used to strengthen oneself. Outside of the medical field, however, there are a number of different analyses that explore positive aspects of shock, particularly through the use of distancing, distraction, and naturalization or normalization mechanisms.

\section{Shock and Nostalgia as Distancing Mechanisms}

Fascinated by modern technologies and modern cities such as Berlin, Naples, Marseilles, and Paris, Benjamin sought to point out that while shock can be directly connected to different forms of trauma, and thus negative in its effect, it can also be experienced as revealing and enchanting. Acknowledging that shock was, to a large extent, a necessary aspect of modernity, he argued that one needed to learn how to adjust the mechanisms of perception in order to allow shocking elements to become less traumatizing and more revealing of how the process of change occurs. His own method for doing so was borrowed from Baudelaire, especially through his concept of the flaneur (or "city wanderer"). ${ }^{14}$ By walking aimlessly through the city and slowing 
his pace down to absorb different elements that the city has to offer, the flaneur learns how to transform shock into moments of reflection and to find beauty in things that would otherwise be dismissed or rejected. What is shocking or out of the ordinary thereby becomes a way of explaining the changes that the city, and society, is undergoing. The process of change becomes written into the "built environment," and can only be decoded by those who are patient enough to uncover its riddles: the flaneurs.

In learning to distance oneself from the immediate and often traumatizing effect of change by adopting the position of an outsider looking in, one can shift positions from being a victim of shock to being an observer of shock. Learning how to take pleasure in what are often perceived as the negative consequences of change (poverty, uncontrolled suburbanization, and the creation of different types of marginalities and outcast characters) is in many ways a survival and coping mechanism, one that puts the present within a larger historical perspective, allowing it to be perceived as a particular moment in time, as opposed to a never-ending struggle. This kind of distancing allows one to open up to change, to embrace it through curious examination as opposed to rejecting it in a defensive gesture that seeks to block out shock often by ignoring its unwanted consequences. This particular view of shock as revelatory and enchanting provides an interesting alternative to Freud's assessment of shock as something negative that forces consciousness into a defensive position allowing the trauma to settle into our unconscious and cause unexpected and often dangerous side effects. ${ }^{15}$

According to Benjamin, the melancholy of the flaneur provides an essential protective shield that separates the self from the violence of the stimuli, allowing them to enter consciousness without necessarily hurting it or overwhelming it. This occurs through a process of distancing in which immediate reality is experienced as something external, to be admired almost as a painting, rather than something of which the flaneur is a constituting element. This distancing can have a number of unwanted consequences. It is often based on a degree of indifference and an assumption of false separation from the object of analysis, thereby creating the impression that one is completely aloof and has no impact on the surrounding environment. Needless to say, this can be particularly dangerous in situations in which this aloofness becomes an excuse for nonaction and increasing indifference to what would otherwise be perceived as a worrisome situation.

Temporary forms of distancing however, such as nostalgia, can at times provide a welcome relief from particularly tense situations. Modern-day nostalgia, particularly as experienced in postcommunist societies, is one example of this type of temporary distancing that 
allows the nostalgic to deal with the consequences of swift change by retreating into an often idealized past. Susan Sontag argues that nostalgia is more than the art of remembering: It is the art of rearranging time according to a more random order than the chronological one, one that favors positive memories. ${ }^{16}$ This selection of positive experiences triggers not only a longing for the past, but also the realization that the present situation is so far from the positive nature of these memories. Loosing the linearity of time through nostalgia allows one to reexperience one's past through idealized moments alone, creating an interesting mechanism of escape from the present and possible projection for the future. However, nostalgia is more than a momentary escape from the present: It is an indisputable critique of the present that for one reason or another fails to deliver similar positive experiences as the past. This critique, embedded in the nostalgic act itself, has direct implications for the way in which the present is perceived and experienced, but more importantly, it can also be seen as prophetic of the future.

Sontag thus argues that Benjamin's nostalgic reflections are not just excuses for reliving positive memories, but rather creative engagements with how the past has helped shape the present and, more importantly, how it is likely to affect the future:

Benjamin regards everything he chooses to recall in his past as prophetic of the future, because the work of memory (reading oneself backward, he called it) collapses time. There is no chronological ordering of his reminiscences, for which he disavows the name of autobiography, because time is irrelevant. . . Memory, the staging of the past, turns the flow of events into tableaux. Benjamin is not trying to recover the past but to understand it: to condense it into its spatial forms, its premonitory structures. ${ }^{17}$

What, then, is Central and Eastern European nostalgia premonitory of? The rise of nationalist and xenophobic movements, or a general increase in conservatism, or simply a need to maintain a certain sense of identity? Current analyses of nostalgia in the Central and Eastern European context, including the former German Democratic Republic, suggest that while nostalgic behavior has for the most part been used as a harmless form of distancing that helps restore a lost sense of identity-as in the case of East German "ostalgia" represented by the revival or celebration of a number of old East German products and linguistic terms, as well as in the case of immigrant or rural communities from Central and Eastern Europe and the former Soviet Union ${ }^{18}$ — can also be particularly harmful by providing 
fertile ground for extreme nationalist and racist movements that seek to present the past in an overly positive light, offering it as a possible alternative to what people are experiencing today. ${ }^{19}$ While most people will recognize that a return to the communist past is not likely and probably not as positive as it may seem, the longing for the past acts as an impediment to a number of new reform and restructuring proposals that are by now perceived as painful and often confusing and inefficient. The allure of a stable and secure past thus risks turning nostalgia into something that is much more than a temporary distancing mechanism, and bringing it closer to a constant state of being, a refusal to accept the present that helps justify radical, and often dangerous, policies toward perceived "destabilizing" elements, including marginal groups such as gypsies, ethnic minorities, and, in more recent cases, immigrants.

This double-edged sword of nostalgia exemplifies how the process of transition in postcommunist societies has been perceived as both a critical opportunity to engage with and question the past as well as a traumatic experience that sometimes can lead to more dangerous mechanisms of escape. Understanding the various ways in which people react to shock, by using it either to creatively engage with the past and make sense of "dreamworlds turned dangerous," or by using it as an illusionary refuge that can provide both comfort as well as justification for punishing harmless groups for various problems, can be particularly insightful when looking at societies in transition. 20

Beyond nostalgia as a particular form of distancing, there are other means of dealing with shock that have been noted in the context of literary and media studies. These means often address shock as a form of revelation or distraction. The following section seeks to address how these different mechanisms of dealing with shock can be particularly telling of its consequences and effects in periods of transition.

\section{Shock as Revelation and Distraction}

By describing Benjamin's concept of shock as the birth of a mode of perception in which sensation and intellect play a predominant role, ${ }^{21}$ Carl Cassegard opens up new possibilities for exploring shock as revelatory both through involuntary critical reflection triggered by flaneries, but, more importantly, through different means of manipulation that seek to prescribe a particular kind of revelation. In his reading of Yasunari Kawabata, Cassegard notes that shock can play an important revelatory role, through the so-called aestheticization of shock, the drawing of shock in a positive light, whereby the thrill of 
shock breaks the continuity and fluidity of experience, revealing something that lies beyond its linearity: an original state of "nothingness," a state that is closer to nature, more open-ended, and in which a breakdown of expectations and an abolition of context occur. ${ }^{22}$ This aesthetization of shock occurs within the fictional context of a novel, so that the effects of shock can be manipulated through a particular use of the intellect to imagine and stretch situations and consequences that might appear different in "real" life. Thus, this return to an original state of nothingness that is made possible by shock seems to be just an overly romantic view of what would otherwise be perceived as confusion and loss of control.

According to Cassegard, shock is welcomed in Kawabata's novels because "consciousness knowingly makes itself defenseless against the shock that will free it from spleen," where "spleen" refers to a Baudelairian concept that describes all that is marginal and seemingly negative. ${ }^{23}$ Again, this seems to be an overly romanticized interpretation of shock in which complete letting go frees someone of fear of consequences. The revelation then becomes that one can only be freed from shock once one allows its full impact to be felt, as opposed to constantly guarding against it. Yet, how these emotional and intellectual revelations of fictional characters can be translated into the experience of shock in periods of transition is yet to be explored. Perhaps upon further exploration one will find that there is nothing romantic about this revelation, and that this sense of letting go, almost an indifference, that develops over time is as dangerous as it appears to be freeing, for it instills a sense of helplessness and victimization by forces against which one has little or no power.

Benjamin would perhaps in many ways agree with Cassegard's positive depiction of shock, at least in the literary context, for his association of shock with nostalgia and remembrance is nothing but a similar escape into the realm of idealized memories in a timeless world frame. Yet shock, as described by Benjamin and even Cassegard, is momentary shock, a shock created by a particular encounter or a particular event. Perhaps what is different about modern shock is its constancy: Shock is no longer just a moment in time, an event, but rather an entire period, an entire lifestyle. One can hardly separate shock from nonshock anymore, as the overwhelming assault of a range of stimuli has made its way into every aspect of our modern lives: from the home environment to the office, from the street experience to our vacations. The revelatory impact of shock may thus be lessened to a point where the escape itself becomes yet another form of shock. The tendency to view shock as a positive experience persists not only in narratives that associate it with the concept of time or change but also with the increasing technologization of modern societies. 
This becomes particularly evident in light of the modern visual technologies used by the media to manipulate shock through the employment of visual stimuli aimed at drawing attention both to the changes brought about by the transition (local news broadcasts are often excellent examples of this) as well as the new freedoms that allow one to explore and manipulate a series of different shocking circumstances through illusionary distractions: shock on the screen or in specially designed safe environments such as amusement parks. In these circumstances, shock does indeed appear as a new form of distraction that is to be enjoyed and explored within safe environments, away from the otherwise very "real" consequences that it can have in everyday life. Using shock as a means of distraction creates a series of different means to approach and explore shock that, at least initially, seem to lie almost in direct opposition to the previously discussed mechanisms of distancing. As we will see in the discussion below, however, this may be just another creative way of retreating into an illusionary visual and sensory world that appears to be much less harmful than the nonvirtual one.

In Central and Eastern Europe, the proliferation of visual media, particularly television, has been unprecedented. The thirst for images has resulted in societies whose entire visual field has changed from one in which time is devoted to collective existence, whether urban or rural, to one in which time is occupied by commercials, Hollywood films, replicas of famous Italian, Spanish, or Portuguese soap operas, talk shows and most recently, reality shows. While the transition towards this has been gradual, television is beginning to play a significant role in most people's lives. In Romania, for example, people have gone from watching television for two hours each day (under Ceausescu's energy-saving regulations) to round-the-clock cable programming, and television subscription rates have increased exponentially. ${ }^{24}$

The television has become a much-needed refuge, an imaginarylife alternative to the hardships faced every day during a transition. Television shows, particularly soap operas are treated as if they were part of everyday life. Characters come alive and become a topic of conversation for many women, who spend their time together talking about the latest thing that happened to the main character. While this form of escape has been noted in a number of contexts throughout the world, the general consensus is that it tends to occur particularly during times of deprivation, social tension and individual as well as collective alienation. ${ }^{25}$ Whether this particular form of escape is positive or not has been much disputed, and the answer depends on how each individual engages with this particular form of escape. What is particularly interesting, however, is understanding how each of these individual searches for escape ends up influencing larger social and 
cultural patterns. Just as Benjamin draws the conclusion that the trauma of war silenced people to a point at which nonverbal communication was preferred (thus the rise of the novel) one can see these forms of escapism through television as the death of other forms of communication, such as the traditional gossip on the village bench, and the emergence of new forms for expressing frustration, such as fantasizing about a different life through identification with a particular character in a soap opera, or discussing events from particular television dramas as if they were real.

More than just a refuge, television has become a way of controlling and imagining outcomes that would otherwise appear uncontrollable in real life. As Patricia Pringle argues, we are "linked to our times not only by the ability but also the desire to see in particular ways." 26 The new technologies of distraction are designed in a way that often gives us the false impression that we can control everything we see: video games, interactive television, and even interactive theater. This often spills into an increasing need to control all representations and interpretations of the real. In her analysis of what she calls "the shock of the real," Beatriz Jaguaribe argues that these tendencies for control can be increasingly dangerous as "both written narrative and visual imagery ... unleash an intense, dramatic discharge that destabilizes notions of reality itself." 27

Using the case of Brazil, Jaguaribe argues that the media shifts too quickly from the extremes of disenchanted images presented by documentaries showing the destitution of slums, the rise in crime, street children, and poverty, to the reenchantment of those same cities through fictional fantasies of wealth, beauty, and the good life. During this emerging crisis of representation, as she calls it, reality appears not only as highly fragmented, but is often confused with the fantasy, whether enchanted or disenchanted. Thus, using the example of the maid in one of Proust's novels, who cries when reading about poverty in a novel yet is unable to relate to similar situations in the real world, Jaguaribe argues that media depictions of the "real" in Brazilian movies and documentaries often fail to provoke sentiments of compassion and pity and instead lead to a more ambiguous response that carries little meaning or overall interpretation:

Such an ambiguity is not related to the subtle, veiled ploys of the narrative or image. After all, the realistic depiction of violence or strong emotional feelings is easily apprehended by readers or viewers. But what is not so easily understood is the meaning of such violence and emotion, not only because reception varies but also because there is no overarching interpretative ethos to provide solace and meaning to such cathartic representations. ${ }^{28}$ 
This is particularly obvious in postcommunist societies, where much of the local news deals with the pathological consequences of the transition: family dramas, mothers killing their children, husbands killing their wives and vice versa, suicides, the rise in violent crime, drug addiction, and disease. The reaction to the news is either one of denial, or one of indifference and even amusement, so that the stories become less real in their consequences and can thus be treated as sources of running jokes, imaginary twists or simply detached events on a screen, as if in a movie. Thus, the often shocking experience of these news reports is transformed into a means of distraction rather than a revelation, almost as if people refuse to take in any more bad news by simply pretending it is not true. While some psychoanalysts would describe this as a natural form of defense against phenomena that would otherwise be too difficult to process, one needs to also consider the collective consequences of these reactions that are likely to lead to increasing indifference when faced with important events as well as to an almost complete lack of empathy and sense of community on which one can rely. ${ }^{29}$ This numbness of the senses, paradoxically caused by overstimulation through technologies such as television as well as other forms of media and publicity mechanisms, might explain the rise of the so-called "pragmatic individual" who seeks nothing but profit, and who is willing to follow his/her goals at all costs to himself and those around him/her. ${ }^{30}$ This move toward extreme pragmatism has been noted by a number of explorers of the Central and Eastern European transitions, including Svasek and Vogt, who see it as extremely worrisome and indicative of the extent to which these societies have changed-to a point where they are almost beyond recognition.

The recently introduced notion of collective culture shock might help explain some of the effects that this change beyond recognition carries with it. Building from the concept of (individual) culture shock, developed to describe the experiences of expatriates who find themselves in unfamiliar environments that they often have to learn to (re)negotiate, the concept of collective culture shock seeks to apply similar feelings of disconnect to contexts in which entire collectives find themselves trapped in unfamiliar environments, such as in the case of transitions. Thus, Feichtinger and Fink argue that one may speak of such a collective culture shock in instances "where an abrupt change in the political system influences the cultural context. ... In this case culture shock is not initiated by the geographical change of going abroad, but is caused by influences on the existing social and cultural system." 31 These abrupt changes result in a need to initiate attempts at rediscovering one's society and, to a certain extent, oneself. 
If periods of transition and radical reform have the power to change one's environment to a point where it becomes unrecognizable, one needs to seriously consider the efforts collectivities have to undertake in order to adjust to these new environments. Returning to the previous discussion of nostalgia, to something that appears almost like a new culture, this adjustment effort might also help explain the longing for a past that felt more like "home" in the context of a present that has radically changed that "home environment" to a point of no return. Perhaps what makes this process even more painful is the fact that it is to a large extent self-inflicted. The desire for change was overwhelming at the time of the 1989 revolutions, and although doubts surrounding the reform or shock-therapy process that followed have persisted, the dream of becoming "like the West" was able to justify the pains inflicted by constant change. While continuing to walk forward toward the now-fulfilled dream of European unification (at least for ten of the postcommunist states), many find themselves looking back toward the past, bidding goodbye to familiar, even if meager, comforts, that they were not quite ready to leave.

Living in a society that does not quite feel like one's own but more like a home away from home can be quite painful, particularly when coupled with the realization that one's home no longer exists. The pain and stress are often further intensified by the literal loss of one's house through the process of denationalization, whereby homes that were nationalized by the communists are now given back to their previous owners, most of whom have either left the country or moved to other areas. This literal loss of one's familiar environment compounds the effects of change, leading to an overwhelming sense of being lost. The fears and pains surrounding the process of denationalization are particularly telling of the trauma associated with the loss of a home (whether literal or not). As Filippo Zerilli, Maruska Svasek, and Carolin Leutloff-Grandits argue in the Romanian, Czech, and Croatian contexts respectively, the emotions associated with the process run quite high, often leading to increased social fragmentation and very mixed feelings with regard to the "democratic transition." 32

In an interesting twist of fate, some of the very leaders of the 1989 revolutions also find themselves entangled in this process. In the Romanian context, Nicolae Badilescu, one of the main leaders of the Timisoara revolutions, confesses in a private interview with the author that, if he could, he would take back his words and actions and go back to the way things were before (the revolution) in an instant. Faced with the very likely possibility that he will be kicked out of his own home as a result of the denationalization process and living on a pension that hardly pays for groceries, his disappointment knows no 
limits and his feelings of guilt run high knowing that, though unwillingly, he caused many other people to find themselves in a similar position. ${ }^{33}$

The collective culture shock implies both metaphorically as well as literally the irrevocable loss of one's home, a loss that was to a large extent self-inflicted, and thus carries a higher level of personal and collective guilt, as well as a constant need to somehow recreate, even if only temporarily, this lost environment.

Beyond practices of distancing such as nostalgia, and distraction through illusionary visuals, so-called normalization and naturalization practices have also been noted. The last part of this article explores the extent to which shock can be "normalized" and whether this is indeed as harmless a coping mechanism as it may initially appear.

\section{Shock and Practices of Normalization}

In his analysis of shock in modernity, Tim Armstrong sees modern shock as directly connected to everyday life and the technologies of the urban such as the telephone, trains, and tramways. ${ }^{34}$ Thus shock need not necessarily come from a particular package of economic and political reforms, but can carry a more or less constant existence through sometimes barely noticeable changes in the technologies surrounding everyday existence. According to this argument, shock can be present in different ways at all points in time (even before the so-called period of modernity), yet is intensified in modern times because of the character as well as the overwhelming presence of these technologies in our everyday lives. The process of normalization occurs almost naturally through a slow familiarization with these technologies that are then taken for granted and become part of our familiar environment.

While limiting shock to technologies seems to rule out a number of other radical changes-from policy to institutional changes-that have a direct effect on societies in general, and societies in transition in particular, it does however point out that the process of normalization is in many ways a must for anyone who is to survive in this shocking environment. If one were to think of normalization outside of the context of increasing technologization, and apply it to other processes of swift change, such as revolutionary or postrevolutionary periods, then the so-called normalizing techniques become particularly important. As both Armstrong and Luke seem to suggest, normalization occurs through an increasing familiarization with change, being simply brought about by time and changing views of the effects 
of the change or of the increasing use of technologies. ${ }^{35}$ However, in the case of the postcommunist context, the process of normalization can also be interpreted in a number of other ways.

First, normalization can occur through a swift redefinition of what it means to be normal. In the case of transition economies, the normal is often defined by the goal toward which they are transitioning, whether toward a particular model country or a specific political and economic system. By accepting a redefinition of what it means to be normal, one almost inevitably has to accept the process that leads to this so-called normality. Thus, within the transition literature, there are countless references to the "need to be normal," and to "be like them" that help justify the painful transition process. Nevertheless, such redefinitions are often accompanied by doubts and hesitations expressed through various forms of nostalgia. 36

Normalization can also occur through a willful ignorance of the process of change. By pretending that change has not actually occurred, by seeking to ignore its consequences, or by mocking change through jokes and irony, a protective shield against shock can be created so that the shock of change appears to be happening somewhere beyond one's own life. This creation of a doubled identity, one directly experiencing change and one feeling outside this change, leads to a confusing and contradictory environment in which people both support and make fun of or even openly reject the same process. This becomes particularly evident in instances where people both support and make fun of a particular political administration, or when a teachers' union goes out in the street to demonstrate for an increase in their salary while at the same time the majority of the demonstrators vote for a party supporting cuts in public management and increased privatization.

Cassegard also addresses this process of what I call double-identity through what he calls naturalization. For him, naturalization means that one has grown used to an environment that was once shocking, where getting used to shock means learning how to live one's public life with shock while spending one's private life in isolation from shock. ${ }^{37}$ Analyzing modern shock through the prism of Marakami Haruki's novels, Cassegard argues that the way in which his characters are able to withstand shock is through a detachment of the mind and the self from relations to other people and things. The process of naturalization of shock is thus one in which the individual detaches him/herself from the surrounding environment to a point where he/she becomes indifferent to change. If modern shock is embedded in all relationships with the outside world, then solitude becomes only a temporary escape, one that is often resisted by our dependence on the outside world. ${ }^{38}$ 
What these alternative interpretations of the process of normalization point out though is that while collectivities can come up with creative ways to withstand or justify shock, to pretend that instances of shock are normal does nothing but add yet another level of stress in which the pretense itself becomes a lie. This kind of environment however is not much different from Václav Havel's famous description of communist Czechoslovakia as "living in a lie." 39 Yet this is a different kind of lie, one that is justified by certain material reminders that one is on the right track. Even if the material reminders are visible mainly on the new billboards dominating the cityscapes of postcommunist societies rather than in people's homes, they affirm that "we can get there one day." If the normal in postcommunist societies today seems to be defined by ownership of an air conditioner or having new low-emission windows, or being able to afford a vacation in Greece, Turkey, or Croatia, then that normal may after all be achievable, although once achieved it may seem less exciting and perhaps more disappointing than one might anticipate.

\section{Conclusion}

This article has tried to establish a series of connections between different interpretations of the concept of shock and the processes of transition and social change. Starting with a critique of economic shock therapy, the article questions the extent to which shock can be perceived as therapeutic and moves on to discuss some of the effects and consequences of shock in the postcommunist transitions of Central and Eastern Europe. By seeking inspiration in a number of different fields, from the medical use of shock therapy, to the concept of shock in psychoanalysis, literature, philosophy, sociology, and media studies, the article has sought to explore how these different meanings can bring out new aspects of the impact of shock in periods of transition. By bringing together different types of literature approaching the concept of shock, I have tried to weave together a number of different debates juxtaposing the negative and positive aspects of shock, different means of adjusting to shock, and the extent to which some practices can be more harmful than others, as well as to discuss the particularities of a more or less self-inflicted shock through the reforms that characterize periods of transition.

Shock becomes a context in which to explore a series of contradictory phenomena, such as enthusiasm about change and but also nostalgia about the past; an obsessive search for the normal and normality but also a rise in a number of different collective and individual pathologies such as suicide, crime, and corruption; and the for- 
mation of new social solidarities generated by illusionary images but also the disintegration of former solidarities through the rise of pragmatism. I have sought to explore these contradictions from different points of view, and to put them in new contexts in order to draw out a series of possible implications and conclusions. Most of these conclusions involve a serious questioning of the extent to which shock can ever be therapeutic by focusing on a number of undesirable consequences of shock: from dangerous forms of nostalgia, to new forms of distancing and distraction that lead to rising levels of apathy, indifference, and distrust, to redefinitions of normality and the "natural" that put increasing pressure on achieving a certain standard of living without questioning the actual benefits that this would bring.

Put in a context of what some perceive to be a successful transition, with much of Central and Eastern Europe already in the European Union, yet which continues to hide many dissatisfactions, traumas and scars, as well as in the context of those countries in the Middle East and Sub-Saharan Africa that are about to be subjected to different forms of shock therapy, this analysis will hopefully encourage others to go beyond the narrow debates on economic shock therapy and explore not just the omelet but also the broken eggs left behind.

\section{Notes}

This article builds upon a chapter in my forthcoming book, Revolution, Democratic Transition and Disillusionment (Manchester/New York: Manchester University Press, 2008). I would like to thank Mustapha K. Pasha and Thomas Diez for their comments and encouragement.

1. Galina Stolyarova, "De-Stress with Shock Therapy," Moscow Times, 11 September 1999.

2. John Marangos, "Shock Therapy and Its Consequences in Transition Economies," Development 48, no. 2 (2005): 70.

3. John Marangos, "Was Shock Therapy Really a Shock?" Journal of Economic Studies 37, no. 4 (2003); Vivek Dehejia, "Will Gradualism Work When Shock Therapy Doesn't?" Economics and Politics 15, no. 1 (2003); Padma Desai, "Beyond Shock Therapy," Journal of Democracy 6, no. 2 (1995).

4. John Marangos, "Was Shock Therapy Consistent with Democracy," Review of Social Economy 62, no. 2 (2004); P. Theodore Gerber and Michael Hout, "More Shock Than Therapy: Market Transition, Employment, and Income in Russia, 1991-1995," American Journal of Sociology 104 (July 1998); Daniel Singer, "Europe's Crises," Social Justice 23, nos. 1-2 (1996).

5. Jeffrey Sachs, "Shock Therapy in Poland: Perspectives of Five Years," The Tanner Lectures on Human Values, University of Utah, 1994.

6. Quoted in Marangos, "Was Shock Therapy Consistent?" note 4.

7. For a more detailed explanation as to how this occurred, see ibid., pp. 229-231. The changes of heart, while initially appearing contradictory, can easily be explained by the fact that the consequences of economic reform were never properly presented to the population at large because shedding 
too negative a light would have insured a negative vote from the very beginning. The more recent controversy (May 2006) surrounding Hungary's prime minister, Ferenc Gyurcsany, and his public admission of lying about the effects of much needed economic reforms in order to insure a yes vote for his party, is indicative of how this process actually occurs: "We will lie to them, administer the painful dose when there is nothing they can do about it, and hope for the best."

8. Marangos, "Shock Therapy and Its Consequences," note 2, p. 72.

9. All quoted in Marangos, "Was Shock Therapy Really a Shock?" note 3, p. 944.

10. Jean MacKenzie, "Were We Really That Naive?" Moscow Times 10 March 2003. Although this article refers specifically to the Russian experience, this can easily be applied to just about every postcommunist experience to varying degrees. While inflation levels recorded in the period immediately following 1989 were indeed different throughout Central and Eastern Europe, there is no question as to the immediate fall in the standard of living for the majority of the population, which is reflected both in the public opinion surveys undertaken by the European Union as well as the Open Society Institute.

11. See testaments in Maruska Svasek, Postsocialism: Politics and Emotions in Central and Eastern Europe (New York/Oxford: Berghahn Books, 2006); Henri Vogt, Between Utopia and Disillusionment: A Narrative of Political Transformation in Eastern Europe (New York/Oxford: Berghahn Books, 2005).

12. Ralf Dahrendorf, After 1989: Morals, Revolution and Civil Society (New York/Oxford: St. Martin's Press/St. Antony's College, 1997); Emile Durkheim, Suicide: A Study in Sociology, translated by John A. Spaulding and George Simpson (New York: The Free Press, 1951); S. N. Eisenstadt, "The Paradox of Democratic Regimes: Fragility and Transformability," Sociological Theory 16, no. 3 (1998); Charles H. Fairbanks, Jr., "Ten Years after the Soviet Breakup: Disillusionment in the Caucasus and Central Asia," Journal of Democracy 12, no. 4 (2001); Sona Hermochova, "Reflections on Living through the Changes in Eastern Europe," Annals of the American Academy of Political and Social Science 552 (1997); Don Kalb and Herman Tak, "The Dynamics of Trust and Mistrust in Poland: Floods, Emotions, Citizenship and the State," in Maruska Svasek, ed., Postsocialism: Politics and Emotions in Central and Eastern Europe (New York/Oxford: Berghahn Books, 2006); George Konrad, The Melancholy of Rebirth: Essays from Post-Communist Central Europe 1989-1994, translated by Michael Henry Heim (New York: Harcourt Brace, 1995).

13. Walter Benjamin, Illuminations, translated by Harry Zohn, Hannah Arendt, ed. (New York: Schocken Books, 1968).

14. Charles Baudelaire, Les Fleurs Du Mal (Boston: David R. Godine, 1985), Charles Baudelaire, Paris Spleen (New York: New Directions Publishing Corporation, 1970).

15. Peter Gay, ed., The Freud Reader (London: Vintage, 1995).

16. Susan Sontag, Under the Sign of Saturn (New York: Anchor Books, 1972).

17. Ibid.

18. Jonathan Bach, “The Taste Remains': Consumption, (N)Ostalgia, and the Production of East Germany," Public Culture 14, no. 3 (2002); Svetlana Boym, "From the Russian Soul to Post-Communist Nostalgia," Representations 49, special issue: Identifying Histories: Eastern Europe Before 
and After 1989 (1995); Patrick Heady and Liesl Miller Gambold, "Nostalgia and the Emotional Economy: A Comparative Look at Rural Russia," in Svasek, note 12.

19. Svetlana Boym, The Future of Nostalgia (New York: Basic Books, 2001); Jason Leboe and Tamara Ansons, "On Misattributing Good Remembering to a Happy Past: An Investigation into the Cognitive Roots of Nostalgia," Emotion 6, no. 4 (2006); Sarah E. Mendelson and P. Theodore Gerber, "Soviet Nostalgia: An Impediment to Russian Democratization," The Washington Quarterly 29, no. 1 (2005-2006); Damien McGuinness, "Goodbye Ostalgia: A New Willingness to Criticize East Germany," Spiegel Online, accessed 2 March 2006.

20. Susan Buck-Morss associates the concept of dreamworlds to modern ideologies such as communism and capitalism, arguing that when untested/uncontrolled, these dreamworlds threaten to transform entire societies into unrealistic theme parks of material promises and desires that are often left unsatisfied and, more importantly, create a need to rely on illusions or dream-wishes in order to withstand less-enchanting everyday realities, Susan Buck-Morss, Dreamworld and Catastrophe: The Passing of Mass Utopia in East and West (Cambridge, Mass.: MIT Press, 2002).

21. Carl Cassegard, "Shock and Modernity in Walter Benjamin and Kawabata Yasunari," Japanese Studies 19, no. 3 (1999).

22. Ibid., p. 242.

23. Ibid., p. 249.

24. These statistics are available on the Romanian Institute for National Statistics website under the Culture and Sports Chapter at: www.insse.ro. The information was accessed on 13 March 2006.

25. See Elihu Katz and David Foulkes, "On the Use of the Mass Media as 'Escape': Clarification of a Concept," The Public Opinion Quarterly 26, no. 3 (1962): 377-388; Leonard Pearlin, "Social and Personal Stress and Escape Television Viewing,” The Public Opinion Quarterly 23, no. 2 (1959): 255-259.

26. Patricia Pringle, "Spatial Pleasures," Space and Culture 8, no. 2 (2005): 155.

27. Beatriz Jaguaribe, "The Shock of the Real: Realist Aesthetics in the Media and the Urban Experience," Space and Culture 8, no. 1 (2005): 70.

28. Ibid., p. 70.

29. Stanley H. Teitelbaum, Illusion and Disillusionment: Core Issues in Psychotherapy (New York: John Aronson, 1999).

30. See a similar argument in Svasek, note 12 and Vogt, note 11.

31. Claudia Feichtinger and Gerhard Fink, "The Collective Culture Shock in Transition Countries-Theoretical and Empirical Implications," Leadership E Organization Development Journal 19, no. 6 (1998).

32. Filippo Zerilli, "Sentiments and/as Property Rights: Restitution and Conflict in Postsocialist Romania"; Maruska Svasek, "Postsocialist Ownership: Emotions, Power and Morality in a Czech Village"; and Carolin LeutloffGrandits, "Claiming Ownership in Postwar Croatia: The Emotional Dynamics of Possession and Repossession in Knin," all in Svasek, note 12.

33. Nicolae Badilescu, interview by author (tape recording, Timisoara, 13 December 2004.

34. Tim Armstrong, "Two Types of Shock in Modernity," Critical Quarterly 42, no. 1 (2000): 60-74.

35. W. Timothy Luke, "Technology as Metaphor: Tropes of Construction, Destruction, and Instruction in Globalization," paper presented at the 
International Studies Association meeting, San Diego, 2006; W. Timothy Luke, Scanning Fast Capitalism: Quasipolitan Order and New Social Flowmations, available at http://www.uta.edu/huma/agger/fastcapitalism/1_1/luke.htm, accessed 15 May 2006.

36. See, for example, the interviews conducted by Beata Barbara Czajkowska, "From Tribunes to Citizens: Polish Intelligentsia During and after Communism," dissertation, University of Maryland, 1999; Vogt, note 11.

37. Carl Cassegard, "Murakami Haruki and the Naturalization of Modernity," International Journal of Japanese Sociology 10, no. 1 (2000): 80-92. 38. Ibid., p. 88.

39. Václav Havel, The Power of the Powerless: Citizens against the State in Central and Eastern Europe (New York: Palach Press, 1985). 